\title{
Highly efficient sulfonic/carboxylic dual-acid synergistic catalysis for esterification enabled by sulfur-rich graphene oxide (GO-S)
}

\author{
Honglei Zhang ${ }^{*[a]}$, Xiang Luo ${ }^{[b]}$, Kaiqi Shi[b], Tao Wu ${ }^{[b, c]}$, Feng He ${ }^{*[d]}$, Shoubin Zhou ${ }^{[e]}$, George Z. \\ Chen ${ }^{[f]}$, and Chuang Peng ${ }^{[a]}$
}

\begin{abstract}
A new sulfonic/carboxylic dual-acid catalyst based on sulfur-rich graphene oxide (GO-S) was readily prepared and used as a highly efficient and reusable solid acid catalyst towards the esterification of oleic acid with methanol for biodiesel production. Higher yields of methyl oleate $(98 \%)$ and over 3 times higher turnover frequencies (TOF) were observed for the GO-S dual-acid catalyst, compared to liquid sulfuric acid or other carbon-based solid acid catalysts. The "acidity" of sulfonic acid groups was enhanced by the addition of carboxylic acid groups since the combination of the two acids enhances their inherent activity by associative interaction.
\end{abstract}

Homogeneous acid catalysts, such as $\mathrm{H}_{2} \mathrm{SO}_{4}$, are widely used in catalytic processes for the manufacture of a range of important chemicals in pharmaceutical, petroleum and the fine chemical industry. ${ }^{[1]}$ However, the use of $\mathrm{H}_{2} \mathrm{SO}_{4}$ causes many problems, such as the difficulty in its separation from the reaction medium, formation of large quantity of wastewater and corrosion to the equipment. ${ }^{[1-2]}$ Therefore, it is desirable to develop highly active, inexpensive, and reusable heterogeneous acid catalysts for various applications. ${ }^{[3]}$ Many solid acid catalysts have been proposed, such as strong acid cation-exchange resin, ${ }^{[4]}$ inorganic oxides including zeolites ${ }^{[5]}$ and metal oxides, ${ }^{[6]}$ silica-based material, ${ }^{[7]} \quad-\mathrm{SO}_{3} \mathrm{H}$-functionalized mesoporous materials, ${ }^{\left[{ }^{[8]}\right.}$ solid superacids, ${ }^{\left[{ }^{[]}\right.}$and $-\mathrm{SO}_{3} \mathrm{H}$-functionalized carbon materials, ${ }^{[10]}$ among which $-\mathrm{SO}_{3} \mathrm{H}$-functionalized carbon materials have emerged as stable, cost-effective and highly active acid catalysts for various acid-catalyzed reactions.

[a] Dr. H. L. Zhang, Prof. \& Dr. C. Peng

School of Resource and Environmental Sciences, Hubei International Scientific and Technological Cooperation Base of Sustainable Resource and Energy, Wuhan University, Wuhan, 430072, P. R. China. Email: Honglei.zhang@whu.edu.cn; 086-27-68775799 (ph); 086-27-68775799 (fax).

[b] Dr. X. Luo, Dr. K. Shi, Prof. \& Dr. T. Wu

New Materials Institute, The University of Nottingham Ningbo China Ningbo, 315100, P.R. China

[c] Prof. \& Dr. T. Wu

Municipal Key Laboratory of Clean Energy Conversion Technologies, The University of Nottingham Ningbo China, Ningbo, 315100, P.R. China.

[d] Prof. \& Dr. F. He

College of Environment, Zhejiang University of Technology, Hangzhou Zhejiang, 310014, China, Email: fenghe@ziut.edu.cn, 086-571-88320054 (ph), 086-571-88320054(fax)

[e] Mr. S. B. Zhou

Huafu High Technology Energy Storage Co., Ltd, Gaoyou High-tec Industrial Park, Yangzhou, Jiangsu, P.R. China

[f] Prof. \& Dr. G. Z. Chen

Department of Chemical and Environmental Engineering, and Advanced Materials Research Group, The University of Nottingham, Nottingham, NG7 2RD, UK

[g] Prof. \& Dr. G. Z. Chen

Department of Chemical and Environmental Engineering, and Energy Engineering Research Group, Faculty of Science and Engineering, The University of Nottingham Ningbo China, Ningbo, China

Supporting information for this article is available on the WWW under http://dx.doi.org/10.1002/cssc.20xxxxxxx.((Please delete if not appropriate))
Recently, "combined acid system" containing dual acids like Brønsted acid assisted Brønsted acid catalysts have received much attention in organic synthesis. ${ }^{[11]}$ Compared with single-acid catalysts with similar acidity, the closely complexes aroused from dual-acid donor and Lewis alkaline substrate through secondary interactions would result in higher reactivity and stereoselectivity. ${ }^{[12]}$ In addition, the enhanced acidity of dual Brønsted acid in catalysts is supposed to bring about higher reactivity while maintaining the selectivity of their double dentate nature. However, the synthesis of dual-acid catalysts usually involved several organic reactions using deadly chemicals under extraordinarily strident conditions. ${ }^{[13]}$ Therefore, it is necessary to develop simple, environmental-benign and recyclable dual-acid catalysts.

Graphene has attracted many research interests owing to its superior high surface areas, distinctive two-dimensional (2-D) structure and extremely high degree of exposure of surface active sites. ${ }^{[14]}$ The most commonly used scalable method for the preparation of graphene involves graphite oxidation and exfoliation, followed by a reduction process to yield reduced graphene oxide (RGO or graphene). Although its exact structural features are not fully understood, graphene oxide (GO) is a nonconductive hydrophilic carbon material with a few layers of graphene that contains a high density of hydrophilic functional groups including hydroxyl and carboxyl groups. ${ }^{[15]}$ As well as providing dual hydrogen bonding, these oxygen-containing functional groups can lead to mild acidity and facilitate their dispersion in polar solvents like water. ${ }^{[16]}$ The applications of GO as an efficient solid catalyst have been explored in some reactions such as oxidation. ${ }^{[16 b]}$ However, to the best of our knowledge, no work has been reported on the direct use of $\mathrm{GO}$ as a solid acid catalyst for biodiesel production through esterification of fatty acids with alcohols. Using $\mathrm{GO}$ as a carrier or vesicle loaded sulfonic and carboxylic acids, a synergistic dual-acid catalysis effect was found to enhance the reactivity and reusability of the solid acid catalyst. In this communication, a novel dual-acid catalyst, i.e., sulfur-rich GO (GOS) was prepared using a simple modified Hummer's method, which effectively catalyzed the esterification of oleic acid and methanol to produce biodiesel (methyl oleate). For rational comparison, two other reference $\mathrm{GO}$ samples were prepared using traditional Hummer's method (GO-2) and another modified Hummer's method (GO-3). Furthermore, GO-S was treated using $\mathrm{H}_{2} \mathrm{SO}_{4}$ to produce sulfonated $\mathrm{GO}$ (s-GO). Five other carbon-based solid acids were also prepared using reported methods. The catalytic activities of all the catalysts for esterification along with Amberlyst-15, the most used and commercially available solid acid and sulfuric acid were also compared. The experimental details of catalyst synthesis and esterification reactions are provided in Supporting Information (SI).

The successful preparation of GO-S and the presence of various chemical functional groups on GO-S were demonstrated using multiple characterization techniques. Visually, the pristine graphite particles are in the form of block-like crystalline carbon, with irregular micro-scale $(<50 \mu \mathrm{m})$ grains (Figure 1a). ${ }^{[17]}$ Unlike the pristine graphite powders, after the harsh oxidation and ultrasonication processes, the graphene oxide sheets became much smaller and transparent (Figure 1b). Some thin flakes were noted due to the decrease of the Van der Waals interactions between the graphene layers, most likely caused by the introduction of the oxygen-containing functional groups. Transmission electron microscopy (TEM) results also show that the prepared GO-S has transparent lamella and irregular edges, indicating GO-S possesses mono- or few-layer planar sheets and 2-D structure 
(Figure 1c), which is in good agreement with the results reported in literature. ${ }^{[18]}$

The successful oxidation of graphite is supported by $\mathrm{X}$-ray diffraction (XRD) analysis (Figure.1d), showing the disappearance of the peak at 26.5 degrees. The graphite exhibited a peak at $26.5^{\circ}(002)$, which is the typical peak of graphite corresponding to the d-spacing of $0.335 \mathrm{~nm}$. $^{[19]}$ The XRD pattern of GO-S shows a new peak at approximately $2 \theta=12.6^{\circ}$ with a significant decrease in graphite crystallinity, indicating a lattice expansion during the harsh oxidation process. ${ }^{[19 a, 20]}$ However, the (002) peak in the graphite disappeared completely in the GO-S. This observation indicates two possible fates of the original graphite powder. It is possible that the graphite could have lost its original structure due to conversion to a non-crystalline form, e.g. amorphous carbon. However, such a structural conversion from crystalline to non-crystalline carbon may be unlikely to occur at the relatively low temperature and ambient pressure in our experiments. More likely, it suggests that the graphite has been successfully oxidized to GO, as reported previously by Xu et al. ${ }^{[20 c]}$ The d-spacing increased for the GO-S to $0.72 \mathrm{~nm}$ is mainly due to various oxygen-containing functional groups between graphite lamellar structures, leading to the swelling between graphene nano-sheets, thus enlarging the $d$-spacing. ${ }^{[20 a, 21]}$

Fourier transform infrared spectroscopy (FTIR) spectra of graphite and GO-S are shown in Figure 1e. No peak is observed in the finger print region for raw graphite while GO-S shows many absorbance peaks of oxygen-containing functional groups on the surface: the deformation vibration and the stretching vibration of $\mathrm{O}$ $\mathrm{H}$ at 1400 and $3440 \mathrm{~cm}^{-1} ;[20 \mathrm{c}]$ the symmetric $\mathrm{O}=\mathrm{S}=\mathrm{O}$ stretching vibrations from $-\mathrm{SO}_{3} \mathrm{H}$ groups at 1000 and $1030 \mathrm{~cm}^{-1}$; $[22]$ the $\mathrm{C}=\mathrm{O}$ stretching vibration of the $-\mathrm{COOH}$ groups at $1620 \mathrm{~cm}^{-1}$ and 1710 $\mathrm{cm}^{-1}$; and the C-O-C vibration from epoxides groups at $1240 \mathrm{~cm}^{-1}$. The Raman spectra of pristine graphite shows a prominent $\mathrm{G}$ peak at $1575 \mathrm{~cm}^{-1}$, the first-order scattering of the $E_{2 g}$ mode for $\mathrm{sp}^{2}$ carbon lattice ${ }^{[23]}$ and a weak $D$ band at $1348 \mathrm{~cm}^{-1}$, the edge or inplane disorder (Figure 1f). ${ }^{[24]}$ The $I_{D} / I_{G}$ of graphite was calculated to be 0.2 due to the large grain size of pristine graphite and little disorder. ${ }^{[19 a]}$ However, the D band at $1348 \mathrm{~cm}^{-1}$ in GO-S became prominent, and the $\mathrm{G}$ band became wide and shifted to $1583 \mathrm{~cm}^{-1}$, indicating the weakness of the $\mathrm{sp}^{2}$ domains and significant disorder from the grain size reduction. Furthermore, the $I_{D} / l_{G}$ value increased to 0.82 , suggesting more structural disorder caused by the oxygencontaining functional groups, which is in consistence with the results found based on the XRD and FTIR analyses.

In the thermo gravimetric analysis (TGA) curves of graphite and GO-S (Figure 1g), graphite shows excellent thermal stability, and the weight loss is only observed at temperatures over $700{ }^{\circ} \mathrm{C}$, suggesting that there are almost no functional groups in the graphite. ${ }^{[25]}$ Three major mass losses are observed from the TGA curve of GO-S. The first $10 \mathrm{wt} \%$ weight loss below $120{ }^{\circ} \mathrm{C}$ is ascribed to the desorption of water adsorbed in GO-S, indicating that GO-S is moderately hygroscopic due to its high content of hydrophilic functional groups on the surface. The second weight loss peak centering at $220^{\circ} \mathrm{C}$ is a result of the decomposition of oxygen-containing functional groups, such as $-\mathrm{OH},-\mathrm{COOH},-\mathrm{SO}_{3} \mathrm{H}$ and $\mathrm{C}-\mathrm{O}-\mathrm{C}$ groups. The weight loss at this stage is about $35 \mathrm{wt}$. \%, which is in good agreement with the elemental analysis results in Table S1 and EDX results in Fig. S4. These results confirm the existence of abundant oxygen-containing functional groups. The third peak over $600{ }^{\circ} \mathrm{C}$ is assigned to the decomposition of graphene framework. ${ }^{[26]}$ Figure $1 \mathrm{~h}$ shows collected C1s XPS spectra revealing one large broad peak, which is most likely a collection of four smaller peaks related to $\mathrm{C}-\mathrm{C}, \mathrm{C}-\mathrm{O}, \mathrm{C}=\mathrm{O}$ and $\mathrm{O}=\mathrm{C}-\mathrm{O}$ appearing at 284.6, 286.9, 287.9 and $289.3 \mathrm{eV}$, respectively. ${ }^{[27]}$ The single peak at $168.4 \mathrm{eV}$ in Figure $1 \mathrm{i}$ represents the absorption peak of $\mathrm{S}$ from $-\mathrm{SO}_{3} \mathrm{H}$ groups. ${ }^{[16 a, 28]}$ These oxygen- containing functional groups, along with its layered microstructure, makes GO-S an excellent catalyst. The successful preparation of GO-S was also confirmed by ultraviolet-visible spectroscopy (UVVis) and optical photographs of dispersions (see Fig. S2, and S3).

The acidity of the catalysts was first measured with a $p H$ electrode (Metrohm) based on a widely used method. ${ }^{[10 \mathrm{e}, 29]}$ The $\mathrm{pH}$ of all the catalysts $(0.3 \mathrm{~g})$ suspended in $27 \mathrm{~mL}$ of $\mathrm{DI}$ water as well as $1.8 \mathrm{mmol} \mathrm{L}^{-1}$ of sulfuric acid, $3.8 \mathrm{mmol} \mathrm{L}^{-1}$ of acetic acid and 3.8

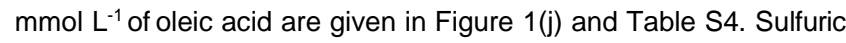
acid displayed the lowest $\mathrm{pH}$ among all the catalysts due to its strong acid nature. The suspension of GO-S displayed higher $\mathrm{pH}$ than s-GO, sulfuric acid and acetic acid; but lower than that of GO2, GO-3 and oleic acid. It is also noted that oleic acid displayed higher $\mathrm{pH}$ compared with acetic acid.
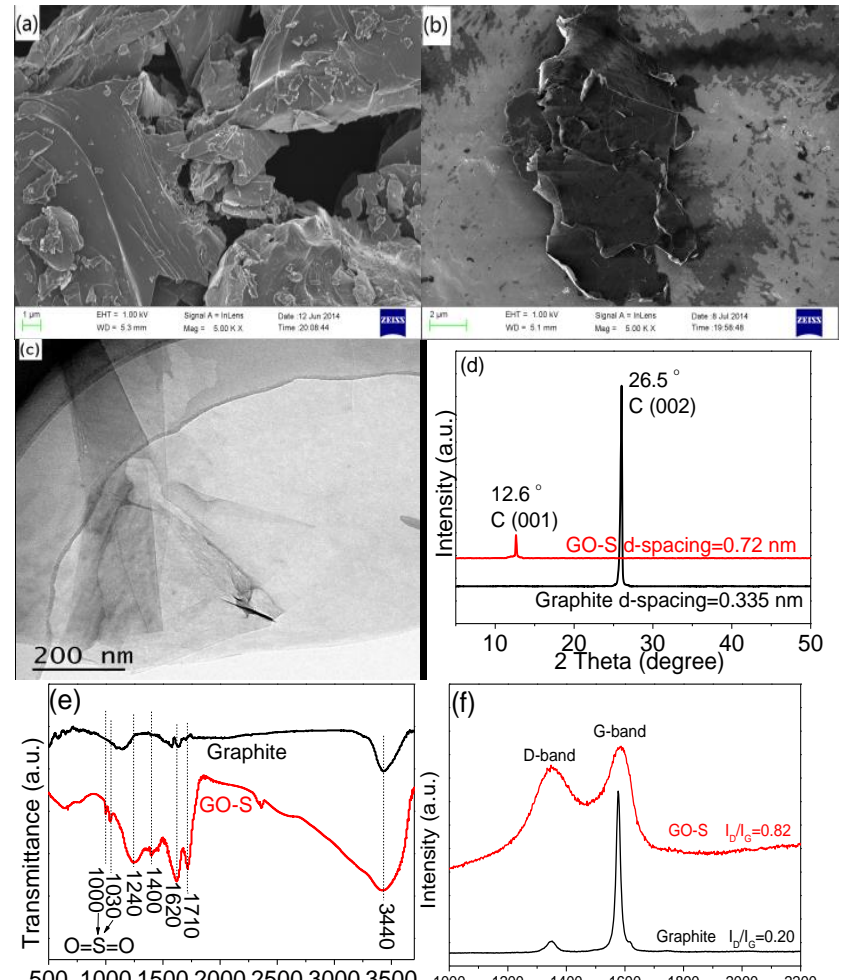

50010001500200025003000
Wave number $\left(\mathrm{cm}^{-1}\right)$
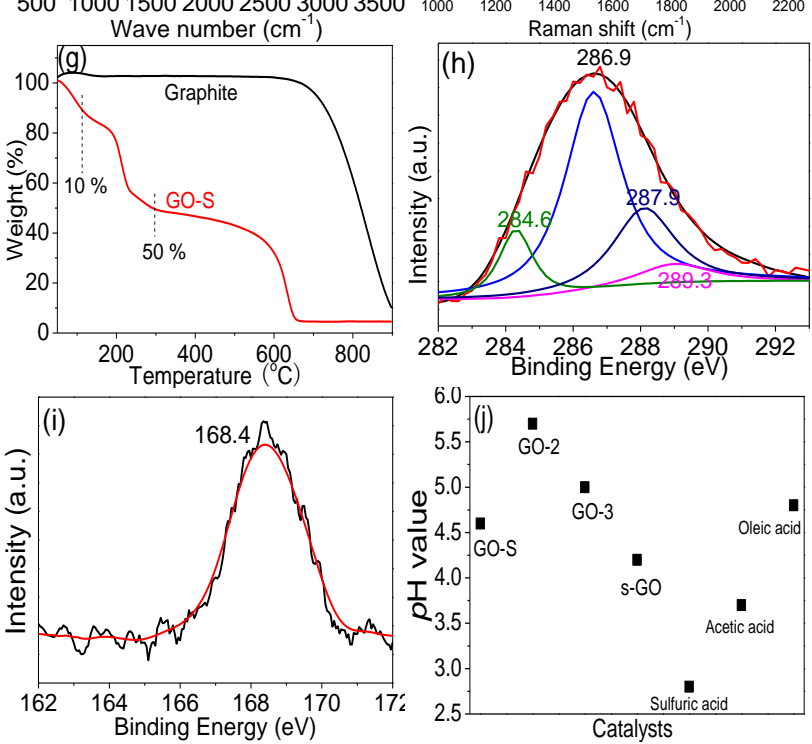

Figure 1 SEM of graphite (a); SEM (b) and TEM (c) of GO-S; XRD (d), FTIR (e), Raman (f), TGA (g) curves of graphite and GO-S; High-resolution C 1s XPS spectra (h), S $2 p$ XPS spectra (i) of GO-S and $p H$ of various catalysts (j). 
To further quantify the acidity, titration of the catalysts was performed and the results are summarized in Table 1. The total acidity of all the $\mathrm{GO}$ samples is higher than that derived from $-\mathrm{SO}_{3} \mathrm{H}$ density (calculated based on $\mathrm{S}$ content) due to the existence of weak acid groups, the $-\mathrm{COOH}$ groups. For s-GO, its sulfur content is significantly higher than that of GO-S (about 2.5 times) and its total acidity is comparable to that of GO-S, suggesting that GO-S has been sulfonated and most of the $-\mathrm{COOH}$ groups have been transformed into $-\mathrm{SO}_{3} \mathrm{H}$ groups (further evidence can be seen in FTIR spectra in Fig. S5). It is also noteworthy that GO-S has higher sulfur content than that of GO-2 and GO-3. The FTIR spectra of GO-S also show stronger vibration of $-\mathrm{SO}_{3} \mathrm{H}$ groups than $\mathrm{GO}-2$ and $\mathrm{GO}-3$ (Fig. S5). This probably results from the preparation method with more $\mathrm{KMnO}_{4}$ used in GO-S preparation. In fact, it was observed that excessive $\mathrm{KMnO}_{4}$ usage in the preparation of $\mathrm{GO}$ can lead to more oxygen-containing functional groups. ${ }^{[16 a]}$

Table 1. Esterification reaction of oleic with methanol using various acid catalysts with the same amount of acid $\left(\mathrm{H}^{+}\right): 0.25 \mathrm{mmol}^{.}$

\begin{tabular}{|c|c|c|c|c|}
\hline Catalysts ${ }^{b}$ & $\begin{array}{l}\text { Total acidity } \\
\left(\mathrm{mmol} \mathrm{g}^{-1}\right)^{\mathrm{c}}\end{array}$ & $\begin{array}{l}-\mathrm{SO}_{3} \mathrm{H} \text { density } \\
\left(\mathrm{mmol} \mathrm{g}^{-1}\right)^{d}\end{array}$ & $\begin{array}{l}\text { Yield at } \\
8 \mathrm{~h}(\%)\end{array}$ & $\begin{array}{c}\text { TOF } \\
\left(10^{-3} s^{-1}\right)\end{array}$ \\
\hline Blank & - & - & 4.2 & - \\
\hline $\begin{array}{l}\text { Acetic } \\
\text { acid }\end{array}$ & - & - & 8.4 & 2.7 \\
\hline $\mathrm{H}_{2} \mathrm{SO}_{4}$ & 20.4 & - & 78.4 & 28.4 \\
\hline $\mathrm{H}_{2} \mathrm{SO}_{4}{ }^{\mathrm{e}}$ & 20.4 & - & 90.7 & 10.7 \\
\hline GO-S & 2.6 & 0.9 & 92.2 & 84.6 \\
\hline GO-2 & 0.2 & 0.2 & 67.7 & 24.3 \\
\hline GO-3 & 0.3 & 0.3 & 71.5 & 25.7 \\
\hline s-GO & 2.5 & 2.1 & 75.7 & 14.9 \\
\hline $\begin{array}{l}\text { Amberlyst- } \\
15\end{array}$ & 5.0 & 4.7 & 62.4 & 2.8 \\
\hline \multicolumn{5}{|c|}{$\begin{array}{l}{ }^{a} \text { Reaction conditions: oleic acid, } 20 \mathrm{~g} \text {; methanol, } 50 \mathrm{~g} \text {; mechanical stirring, } \\
\text { rate } 360 \mathrm{rpm} \text {; reaction temperature, } 338 \mathrm{~K} \text {; and reaction time, } 8 \mathrm{~h} \text {; }{ }^{\circ} \text { the } \\
\text { detailed preparation processes of all the catalysts were all listed in ESIt. } \\
\text { Total acidity calculated by acid-base titration with } \mathrm{NaOH}(0.1 \mathrm{M}) \text {. } \\
\text { Estimated from the sulfur elemental analyzer by assuming that all sulfur are } \\
\text { origin from }-\mathrm{SO}_{3} \mathrm{H} \text { groups. }{ }^{e} \mathrm{H}^{+} \text {amount, } 1 \mathrm{mmol} \text {. }\end{array}$} \\
\hline
\end{tabular}

The GO samples along with $\mathrm{H}_{2} \mathrm{SO}_{4}$, acetic acid and Amberlyst15 were then used in the esterification of oleic acid with methanol to evaluate their catalytic activity and the results are summarized in Figure 2 and Table 1. The esterification reaction was a pseudo-firstorder reaction during the first 4 hours and reached equilibrium after 8 hours (Figure 2a). Based on the calculation of the reaction rate constant $(\mathrm{k})$ and the initial rates $\left(\mathrm{kC}_{0} \mathrm{~g}^{-1}\right.$ catalyst), the turnover frequencies (TOFs) (initial rates per $-\mathrm{SO}_{3} \mathrm{H}$ densities) can be obtained, as shown in Table 1. The control experiment was carried out and the yield of methyl oleate without any catalyst was only $4.2 \%$. Experiments were conducted to study the catalytic activity and TOF of esterification by various amounts of sulfuric acid to establish the selection of acid amount for catalytic performance comparison (Table 1 and Fig. S6). The sulfuric acid amount had a notable effect and the reaction could not proceed efficiently with only a small amount of sulfuric acid due to the lack of catalytic sites. The yield of methyl oleate increased greatly from 78.4 to $90.7 \%$ with the $\mathrm{H}^{+}$amount of sulfuric acid increased from 0.25 to 1 mmol. It seems meaningless to further increase the amount of $\mathrm{H}^{+}$to $10 \mathrm{mmol}$ since esterification with 1,5 and $10 \mathrm{mmol} \mathrm{H}^{+}$had almost the same final oleate yield (around $93.0 \%$ ). However, the TOF value decreased dramatically with the $\mathrm{H}^{+}$amount increased from
0.25 to $1 \mathrm{mmol}$ (Table 1). Therefore, $0.25 \mathrm{mmol} \mathrm{H}^{+}$was used in the following experiments.

GO-S exhibited the highest TOF and oleate yield (92.2\%) among all the catalysts. The GO-S showed a higher activity than Amberlyst-15 despite that the latter has higher $-\mathrm{SO}_{3} \mathrm{H}$ density. Also, the TOF value by Amberlyst- 15 was calculated to be $2.8 \times 10^{-3} \mathrm{~s}^{-1}$, which is 10 times lesser than that of $\mathrm{H}_{2} \mathrm{SO}_{4}\left(28.4 \times 10^{-3} \mathrm{~s}^{-1}\right)$. This result is in good agreement with the data in previous literature. ${ }^{[22]}$ It is interesting to see that $\mathrm{s}-\mathrm{GO}$ performed less well compared with GO-S in catalyzing esterification and the oleate yield was only $75.7 \%$ after 8-hour reaction despite s-GO contains a lot more $\mathrm{SO}_{3} \mathrm{H}$ and has similar total acidity. Since one dramatic difference between GO-S and s-GO is the low content of - $\mathrm{COOH}$ groups in s$\mathrm{GO}$, it is likely that there is an enhancement of $-\mathrm{SO}_{3} \mathrm{H}$ "acidity" by the combination with $-\mathrm{COOH}$ groups in catalyzing esterification because combining the two acidic groups could bring out their inherent reactivity by associative interaction. ${ }^{[11 b]}$ To verify this proposition, we performed additional experiments using acetic acid as a model carboxylic acid, the results are shown in Fig. S7. The oleate yield was only $8.4 \%$ and $47.9 \%$, respectively, when acetic acid $(0.018 \mathrm{~g})$ and $\mathrm{s}-\mathrm{GO}(0.085 \mathrm{~g})$ (corresponding to the molar concentrations of $-\mathrm{SO}_{3} \mathrm{H}$ and $-\mathrm{COOH}$ in the GO-S) were used as separate catalysts. However, when acetic acid and S-GO were used together as co-catalyst, the oleate yield reached $82.5 \%$, which is much higher than the sum of the oleate yields (56.3\%) by the two single catalysts. Additionally, the calculated TOF of the cocatalyst is $52.8 \times 10^{-3} \mathrm{~s}^{-1}$, which is much greater than that of s-GO $\left(14.9 \times 10^{-3} \mathrm{~s}^{-1}\right)$. It is also noteworthy that despite having the same amount of $-\mathrm{COOH}$ and $-\mathrm{SO}_{3} \mathrm{H}$, the yield by GO-S was $16 \%$ higher than that by the co-catalyst. This might result from the enrichment of oleic acid and methanol near the $-\mathrm{SO}_{3} \mathrm{H}$ groups on the graphene sheets in GO-S through adsorption and hydrogen bonding, which facilitated the reaction. ${ }^{[22]}$ It is also noted that acetic acid did not compete with oleic acid for esterification since no products other than oleate were detected. There are mainly two possible explanations for this phenomenon. The first one is that the adsorption-desorption equilibrium on the surface of the carbon play a significant role in enriching oleic acid near the active sites and favors the access of the reactants to the $-\mathrm{SO}_{3} \mathrm{H}$ groups. The second one is that acetic acid is a stronger acid than oleic acid (Figure 1(j)) and therefore acetic acid prefers to be an acid catalyst, rather than a reactant. ${ }^{[22]}$

It has been pointed out that the synergistic effect between defect sites and functional groups could promote the catalytic activity of carbon-based catalysts in hydrolysis reaction. ${ }^{[19 c]}$ The catalytic effect of defect sites on esterification should also be scrutinized in this study. FTIR and elemental analysis results of GO-S and s-GO showed that different functional groups were imparted successfully to the graphene structure and GO-S possesses much higher $\mathrm{COOH} / \mathrm{SO}_{3} \mathrm{H}$ ratio (1.87) than that of S-GO (0.17). Based on the Raman spectrum shown in Fig. S8, GO-S and s-GO has almost the same $I_{D} / I_{G}$ values (i. e., 0.8), suggesting they have similar disorder or defect degree and the sulfonation process (from GO-S to s-GO) did not affect the structural integrity. However, the catalytic activity and TOF value of s-GO is significantly lower than that of GO-S. Therefore, defect sites should not have played significant role in promoting catalytic activity of esterification.

Based on the calculation of the reaction rate constant $(k)$ at different reaction temperatures, the apparent activation energies of esterification by GO-S, s-GO and "s-GO with acetic acid" were calculated using Arrhenius equation (Fig. S9).

$\ln k=-E_{\mathrm{a}} / R T+\ln A$ 
where $k$ is the reaction rate constant $\left(\mathrm{h}^{-1}\right), E_{\mathrm{a}}$ is the apparent activation energy $\left(\mathrm{kJ} \mathrm{mol}^{-1}\right), A$ is pre-exponential factor $\left(\mathrm{h}^{-1}\right), R$ is universal gas constant, and $T$ is the reaction temperature (K). The plot of Ink versus $1 / T$ can be represented by a straight line and $E_{\mathrm{a}}$ of esterification by s-GO is determined to be $41.9 \mathrm{~kJ} \mathrm{~mol}^{-1}$. The apparent activation energy decreased to 34.3 $\mathrm{kJ} \mathrm{mol}^{-1}$ when acetic acid was mixed with s-GO as a "co-catalyst", explaining the enhancement of $-\mathrm{SO}_{3} \mathrm{H}$ "acidity" by the combination with $-\mathrm{COOH}$ groups in catalyzing esterification. The apparent activation energy of GO-S was $25.7 \mathrm{~kJ} \mathrm{~mol}^{-1}$, lower than the value of the "co-catalyst". This explains that GO-S surface also plays an important role in facilitating the esterification reaction, for example through the enrichment of reactants as discussed earlier.

The synergistic effect between $-\mathrm{SO}_{3} \mathrm{H}$ and $-\mathrm{COOH}$ groups also explains the higher oleate yield and TOF of GO-S over GO-2 and GO-3, which have $-\mathrm{COOH} /-\mathrm{SO}_{3} \mathrm{H}$ of 0.17 and 0.19 , respectively. It is interesting that s-GO showed lower TOF than those of GO-2 and GO-3 although they have similar $-\mathrm{COOH} /-\mathrm{SO}_{3} \mathrm{H}$ ratio, indicating that the accessibility of the $-\mathrm{SO}_{3} \mathrm{H}$ groups is reduced when its density is too high. Besides, the synergistic effect also explains the higher TOF and oleate yield of GO-S than those of much stronger acid catalysts such as liquid sulfuric acid (Figure 2 a and Table 1) and Amberlyst-15, which do not contain - $\mathrm{COOH}$ groups.

The mechanism of esterification catalyzed by strong acid catalysts containing $-\mathrm{SO}_{3} \mathrm{H}$ groups was widely studied and is illustrated in Fig. S10. ${ }^{[30]}$ In this well-documented mechanism, methanol does not participate in the reaction until the second step. This is mainly due to the fact that $-\mathrm{SO}_{3} \mathrm{H}$ is a strong acid group whilst methanol is a weak base according to the Lewis acid-base theory. Therefore, in the presence of only $-\mathrm{SO}_{3} \mathrm{H}$, it is too strong to protonate the methanol molecule. However, when a weak acid, e.g. acetic acid, is present or added, its deprotonated form can generate hydrogen bond with the $-\mathrm{OH}$ group in the methanol, providing a fraction of negative charge to the oxygen in the methanol. This in turn helps increase the nucleophilicity of the methanol, and hence the reaction rate and the yield of esterification. The mechanism of esterification catalyzed by GO-S was then proposed based on the above discussions and is illustrated in Figure 3. In the first step, two processes occur simultaneously: a) the protonation of the carbonyl group leads to the generation of carbocation and $b$ ) the deprotonation of the $-\mathrm{COOH}$ groups and the formation of "methanol with negative charge". In the second step, the tetrahedral intermediate was generated after nucleophilic attack of the negative charge with both the methanol molecule and "methanol with negative charge". In the final step, the proton was removed from the unstable intermediate and methyl oleate and water was produced; concurrently, the catalyst was regenerated to start another catalytic cycle.
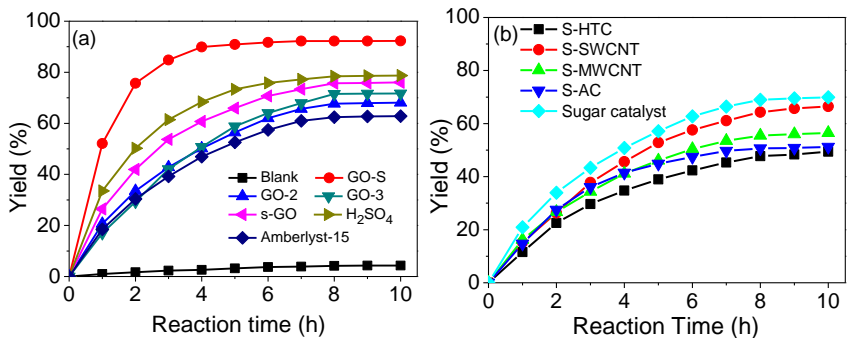

Figure 2 Esterification of oleic acid with methanol by different catalysts with the same amount of acid $\left(\mathrm{H}^{+}\right): 0.25 \mathrm{mmol}$. (a: graphene oxide materials, sulfuric acid and Amberlyst-15; b: other carbon-based solid materials).

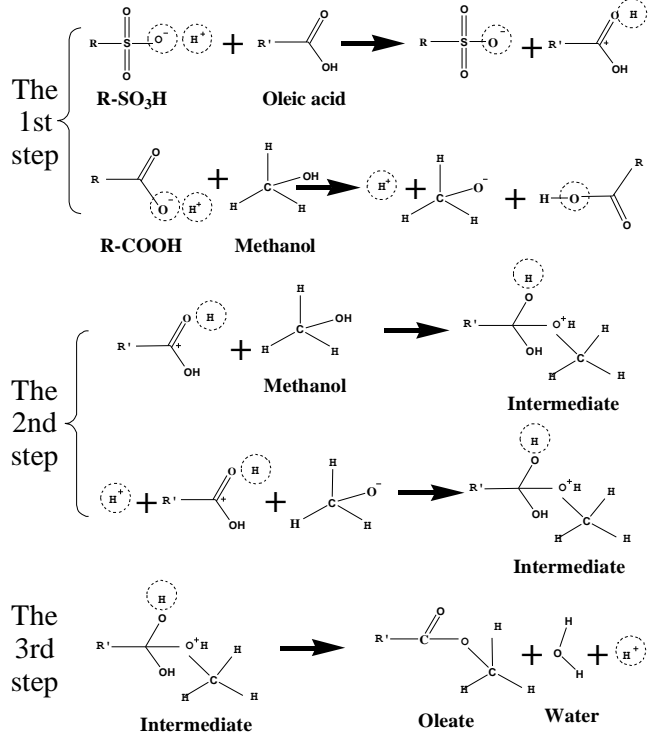

Figure 3 Proposed esterification process catalyzed by GO-S

To further show the superior catalytic activity of GO-S, it was compared with five other typical carbon-based solid catalysts, including three 3-D catalysts (the sulfonated activation carbon (S$\mathrm{AC}$ ), the sulfonated hydrothermal carbon (S-HTC), ${ }^{[22]}$ and the sugar catalyst, ${ }^{[31]}$ ) and two 1-D catalysts (the sulfonated single-walled carbon nanotube (S-SWCNT) ${ }^{[32]}$ and the sulfonated multiple-walled carbon nanotube (S-MWCNT) ${ }^{[32]}$ ) (Figure $2 \mathrm{~b}$ and Table S2). In general, the oleate yield and TOF number of the 2-D, - $\mathrm{COOH}$-rich GO-S are much higher. The order of the TOF numbers for the 3-D catalysts is sugar catalyst $>\mathrm{S}-\mathrm{HTC} \approx \mathrm{S}-\mathrm{AC}$. This can be explained by the high $-\mathrm{COOH} /-\mathrm{SO}_{3} \mathrm{H}$ ratio in the sugar catalyst resulting in stronger synergistic effects (Table S2). The higher TOF of GO-3 over S-AC, which has similar $-\mathrm{COOH} /-\mathrm{SO}_{3} \mathrm{H}$ ratio and acidity, further reveals that the 2-D structure of GO favours the heterogeneous liquid-solid esterification reaction as its layer morphology maximizes the solid/liquid interface and minimizes the mass transfer resistance. For the catalysts with 1-D structure, SSWCNT has similar TOF number with that of S-MWCNT although $\mathrm{S}$-SWCNT has lower $-\mathrm{COOH} /-\mathrm{SO}_{3} \mathrm{H}$ ratio and much lower total acidity. This is mainly because of the single-walled structure and higher exposure of active sites, which makes S-SWCNT possess better affinity to the reactants. ${ }^{[32]}$

Furthermore, the reusability of all the four GO catalysts were investigated. The esterification reactions by all the GO catalysts were performed over a prolonged time $(12 \mathrm{~h}$, equilibrium reached in $8 \mathrm{~h}$, please see Fig. S14). GO-S shows dramatically superior reusability compared to the other three GOs (Figure 4 and Table S3). Only mild deactivation occurred for GO-S after three runs with oleate yield of $8 \mathrm{~h}$ reduced from $92.2 \%$ to $87.5 \%$. However, much more significant deactivation was observed for GO-2 (from $67.7 \%$ to $50.6 \%$ ), GO-3 (from $71.5 \%$ to $52.2 \%$ ) and s-GO (from $75.7 \%$ to $65.4 \%$ ). After four cycles of reuse all the four catalysts showed a slight decline in yield. Nevertheless, it can be seen that GO-S has performed notably better than the other three catalysts against deactivation. For example, after four cycles of reuse, the decline in $8 \mathrm{~h}$ yield was $5.4 \%$ for GO-S, but $26.1 \%, 27.8 \%$, and $11.6 \%$ for GO-2, GO-3, and s-GO, respectively (Table S6). In addition, the decline in $1 \mathrm{~h}$ yield was $25.0 \%, 34.8 \%, 50.5 \%$ and $40.5 \%$ for GO$\mathrm{S}, \mathrm{GO}-2, \mathrm{GO}-3$ and s-GO, respectively. All these results suggested that GO-S possess superior reusability. This superior reusability can be attributed to the markedly higher $-\mathrm{COOH}$ contents (1.68 
$\left.\mathrm{mmol} \mathrm{g}{ }^{-1}\right)$ of GO-S than the other three $\left(0.03,0.05,0.35 \mathrm{mmol} \mathrm{g}^{-1}\right.$ for GO-2, GO-3 and s-GO, respectively).

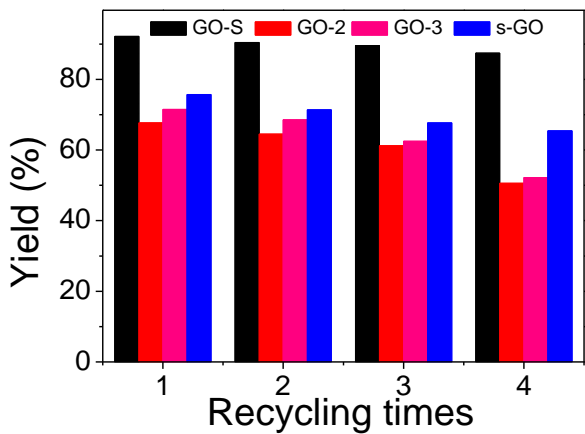

Figure 4 The catalytic performances of all the GO catalysts versus recycling times (reaction time: $8 \mathrm{~h}$ )

It has been recognized that the leaching of sulfonated groups is a common problem for $-\mathrm{SO}_{3} \mathrm{H}$-functionalized carbon materials. ${ }^{[10 \mathrm{c}]}$ Therefore, the sulfur contents in the reaction solutions before and after esterification were tested by a micro-coulometry analyzer and the results were illustrated in Table S5. The sulfur contents in the reaction mixture before and after each esterification run tested were almost the same ( 21.3 ppm), which suggests that there was no leaching of sulfur from GO-S during esterification. In addition, the leaching of sulfur content from GO-S was investigated by analyzing the elemental composition of GO-S before and after the esterification and no leaching of $S$ from the catalyst is observed even after 4 runs (Table S1). This information demonstrated that the slight loss of the the catalyst reactivity was not due to the hydrolysis of $-\mathrm{SO}_{3} \mathrm{H}$ groups, but because of the sulfonted groups being blocked by the accumulated byproducts i. e. water. ${ }^{[10 c, 33]}$

In conclusion, we demonstrated a simple synthesis method to produce GO-S as a cost-effective, highly efficient, and reusable dual-acid carbon-based solid acid catalyst for the esterification of oleic acid with methanol. GO-S showed superior catalytic performance (activity and reusability) and much higher TOF number compared with other conventional carbon-based solid acid catalysts. There are two key properties leading to its excellent catalytic performance: 1) the 2-D layered structure and 2) strong synergistic effect between $-\mathrm{SO}_{3} \mathrm{H}$ and $-\mathrm{COOH}$ groups on graphene nanosheets. This material holds great potential in catalysing the esterification of waste fatty acids to produce biodiesel.

\section{Acknowledgements}

This research was partially supported by the National Natural Science Foundation of China (No. 51308312, 21403119), Ningbo Bureau of Science and Technology under its Innovation Team Scheme (2012B82011) and Major Research Scheme (2012B10042), and the Ningbo Municipal Government (3315 plan and the IAMET Special Fund, 2014A35001-1)

Keywords: Dual-acid catalyst - solid acid - esterification • heterogeneous catalysis

[1] J. Ji, G. Zhang, H. Chen, S. Wang, G. Zhang, F. Zhang, X. Fan, Chem. Sci. 2011, 2, 484-487.

[2] a)H. Zhang, J. Gao, Z. Zhao, G. Z. Chen, T. Wu, F. He, Catal. Sci. Tech. 2016, 6, 5590-5598; b)G. S. Foo, A. H. Van Pelt, D. Krötschel, B. F. Sauk, A. K. Rogers, C. R. Jolly, M. M. Yung, C. Sievers, ACS Sustain. Chem. Eng. 2015, 3, 1934-1942.

[3] a)K. Wilson, A. F. Lee, Catal. Sci. Tech. 2012, 2, 884; b)C. Sievers, I. Musin, T. Marzialetti, M. B. Olarte, P. K. Agrawal, C. W. Jones, ChemSusChem 2009, 2, 665-671.
[12] A. G. Schafer, J. M. Wieting, T. J. Fisher, A. E. Mattson, Angew. Chem. Int. Ed. 2013, 125, 11531-11534.

[13] Y. Kobayashi, Y. Taniguchi, N. Hayama, T. Inokuma, Y. Takemoto, Angew. Chem. Int. Ed. 2013, 52, 11114-11118.

[14] Y. Sun, Q. Wu, G. Shi, Energy Environ. Sci. 2011, 4, 11131132.

[15] a)C. M. Daniela, V. K. Dmitry, Jacob M. Berlin, Alexander Sinitskii, Zhengzong Sun, Alexander Slesarev, Lawrence B. Alemany, Wei Lu, J. M. Tour, ACSnano 2010, 4, 48064814; b)J. Kim, L. J. Cote, F. Kim, W. Yuan, K. R. Shull, J. Huang, J. Am. Chem. Soc. 2014, 132, 8180-8186; c)Anton Lerf, Heyong He, Michael Forster, J. Klinowski, J. Phys. Chem. B. 1998, 102, 4477-4482.

[16] a)Z. Wei, Y. Yang, Y. Hou, Y. Liu, X. He, S. Deng, ChemCatChem 2014, 6, 2354-2363; b)D. R. Dreyer, H. P. Jia, C. W. Bielawski, Angew. Chem. Int. Ed. 2010, 49, 6813-6816

[17] F. Ding, W. Xu, D. Choi, W. Wang, X. Li, M. H. Engelhard, X. Chen, Z. Yang, J. Zhang, J. Mater. Chem. 2012, 22 12745-12751.

[18] V. K. Gupta, N. Atar, M. L. Yola, Z. Ustundag, L. Uzun, Water Res. 2014, 48, 210-217.

[19] a)I.-Y. Jeon, Y.-R. Shin, G.-J. Sohn, H.-J. Choi, S.-Y. Bae, J. Mahmood, S.-M. Jung, J.-M. Seo, M.-J. Kim, D. W. Chang, L. Dai, J.-B. Baek, P. Natl. Acad. Sci. USA 2012, 109, 5588-5593; b)Y. Zhang, D. Book, J. Phys. Chem. C. 2011, 115, 25285-25289; cG. S. Foo, C. Sievers, ChemSusChem 2015, 8, 534-543.

[20] a)P. Shi, R. Su, F. Wan, M. Zhu, D. Li, S. Xu, Appl. Catal., B 2012, 123-124, 265-272; b)S. Stankovich, D. Dikin, H. B. G. Dommett, M. K. Kohlhaas, J. E. Zimney, A. E. Stach, D. R. Piner, T. S. Nguyen, S. R. Ruoff, Nature 2006, 442, 282-286; c)Y. Xu, H. Bai, G. Lu, C. Li, G. Shi, J. Am. Chem. Soc. 2008, 130, 5856-5857.

[21] G. M. Scheuermann, L. Rumi, P. Steurer, W. Bannwarth, R. Mulhaupt, J. Am. Chem. Soc. 2009, 131, 8262-8760.

[22] J. A. Macia-Agull, M. Sevilla, Maria A. Diez, A. B. Fuertes, ChemSusChem 2010, 3, 1352-1354.

[23] a)F. Tuinstra, J. L. Koenig, The Journal of Chemical Physics 1970, 53, 1126-1130; b)S. Stankovich, D. A. Dikin, 
R. D. Piner, K. A. Kohlhaas, A. Kleinhammes, Y. Jia, Y. Wu, S. T. Nguyen, R. S. Ruoff, Carbon 2007, 45, 1558-1565.

[24] W. Wang, J. Yu, Q. Xiang, B. Cheng, Appl. Catal., B 2012 119-120, 109-116.

[25] T. Kuila, A. K. Mishra, P. Khanra, N. H. Kim, J. H. Lee Nanoscale 2013, 5, 52-71.

[26] F. Liu, J. Sun, L. Zhu, X. Meng, C. Qi, F.-S. Xiao, J. Mater. Chem. 2012, 22, 5495-5502.

[27] G. Chen, B. Fang, Bioresour. Technol. 2011, 102, 2635 2640.

[28] X. Liang, M. Zeng, C. Qi, Carbon 2010, 48, 1844-1848.

[29] H. Markus, P. Mäki-Arvela, N. Kumar, N. V. Kul'kova, P Eklund, R. Sjöholm, B. Holmbom, T. Salmi, D. Y. Murzin, Catal. Lett. 2005, 103, 125-131.
[30] a)R. Tesser, L. Casale, D. Verde, M. Di Serio, E. Santacesaria, Chem. Eng. J. 2010, 157, 539-550; b)J. Li, Y J. Fu, X. J. Qu, W. Wang, M. Luo, C. J. Zhao, Y. G. Zu, Bioresour. Technol. 2012, 108, 112-118.

[31] M. Toda, A. Takagaki, M. Okamura, J. N. Kondo, S. Hayashi, K. Domen, M. Hara, Nature 2005, 438, 10

[32] H. Yu, Y. Jin, Z. Li, F. Peng, H. Wang, J. Solid State Chem. 2008, 181, 432-438.

[33] C. A. Deshmane, M. W. Wright, A. Lachgar, M. Rohlfing, Z Liu, J. Le, B. E. Hanson, Bioresour. Technol. 2013, 147, 597-604.

Received:

Published online: 


\section{Entry for the Table of Contents}

\section{COMMUNICATION}

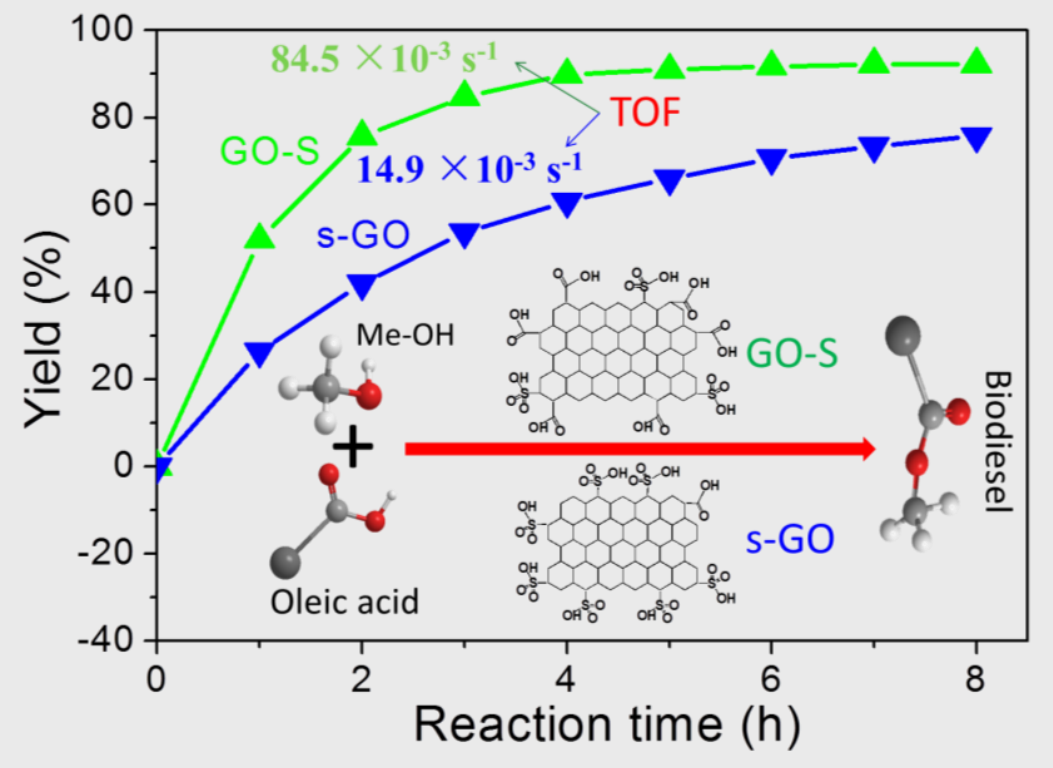

The presence of - $\mathrm{COOH}$ groups significantly promote the biodiesel yield and TOF due to the synergistic effect between $-\mathrm{SO}_{3} \mathrm{H}$ groups and $-\mathrm{COOH}$ groups.
Honglei Zhang*[a], Xiang Luo ${ }^{[b]}$, Kaiqi Shi ${ }^{[b]}$, Tao $\mathrm{Wu}^{[\mathrm{b}, \mathrm{c}]}$, Feng $\mathrm{He}^{*[\mathrm{~d}]}$, Shoubin Zhou ${ }^{[e]}$, George Z. Chen ${ }^{[f]}$, and Chuang Peng[a]

Page No. - Page No.

Title: Highly efficient sulfonic/ carboxylic dual-acid synergistic catalysis for esterification enabled by sulfur-rich graphene oxide (GO-S) 